\title{
Relações de ofício e de saberes entre o naturalista Joaquim Veloso de Miranda e seus auxiliares em Minas Gerais (1780-1805)
}

\author{
Craft and knowledge relations between the Portuguese-Brazilian naturalist Joaquim \\ Veloso de Miranda and his assistants in Minas Gerais (1780-1805)
}

Márcio Mota Pereira ${ }^{1}$

\begin{abstract}
Resumo: As últimas duas décadas do século XVIII marcam o início de um processo de reorientação política e econômica de Portugal para com suas conquistas. Em Minas Gerais, em função da diminuição das atividades mineradoras, o Estado português encontra na História Natural uma nova perspectiva para auferir receitas e dinamizar a economia colonial e reinol. Utilizando-se na maioria das vezes de profissionais ilustrados que frequentaram a Universidade de Coimbra reformada, Portugal deu início a uma complexa atividade de troca de exemplares dos três Reinos da natureza, confiando ainda a estes delegados outras atividades como a própria dinamização desse processo em seus domínios geográficos. Nestes sertões, o naturalista lusobrasileiro Joaquim Veloso de Miranda foi o responsável por coordenar as atividades inerentes a esta nova política de desenvolvimento econômico, bem como por instruir e comandar seus auxiliares nas várias atividades que este esforço demandava. A presente comunicação tem por objetivo apresentar os processos que envolvem a transmissão de conhecimentos no âmbito das relações de trabalho e servidão, inclusive, direcionadas às atividades que perpassavam a História Natural, entre o naturalista em questão e seus auxiliares, no intuito de esclarecer ainda mais os préstimos realizados por esses homens para atender às demandas da Coroa portuguesa. Utilizamos, para tanto, da análise de fontes primárias, muitas das quais inéditas; de fontes impressas e, também, da revisão bibliográfica, por meio da qual buscamos compreender alguns aspectos interessantes sobre o envolvimento de auxiliares e escravizados nas práticas filosóficas e científicas nas Minas setecentistas.
\end{abstract}

Palavras-chave: Joaquim Veloso de Miranda; História Natural; Minas Gerais.

Abstract: The last two decades of the eighteenth century mark the beginning of a process of political and economic reorientation of Portugal towards its achievements. In Minas Gerais, due to the decrease in mining activities, the Portuguese State finds in Natural History a new perspective to earn revenues and boost the colonial economy. Using mostly illustrated professionals who attended the reformed University of Coimbra, Portugal began a complex activity of exchanging copies of the three Kingdoms of nature, entrusting to these delegates other activities as the dynamization of this process in their own. geographic domains. In these hinterlands, the Luso-Brazilian naturalist Joaquim Veloso de Miranda was responsible for coordinating the activities inherent in this new economic development policy, as well as instructing and commanding his assistants in the various activities that this effort demanded. This communication aims to present the processes that involve the transmission of knowledge in the context of labor relations and servitude, including, directed to the activities that ran through Natural History, between the naturalist in question and his assistants, in order to clarify further the loans made by these men to meet the demands of the Portuguese Crown. For this, we use the analysis of primary sources, many of which are unpublished; from printed sources and also from the bibliographic review, through which we seek to understand some interesting aspects about the involvement of auxiliaries and enslaved people in the philosophical and scientific practices in 18th century Minas.

Keywords: Joaquim Veloso de Miranda; Natural History; Minas Gerais.

\footnotetext{
${ }^{1}$ Doutor em História pela Universidade Federal de Minas Gerais. E-Mail: drmmota@yahoo.com.br
} 


\section{Introdução ${ }^{2}$}

Com a retração na produção aurífera verificada a partir da década de 1760 e, sobretudo, ao longo das últimas duas décadas daquele século, Portugal realizou inúmeras ações com o objetivo de reorientar economicamente suas finanças, muitas vezes por intermédio de medidas que foram consideradas pouco ortodoxas pelas elites mineiras, como o cerceamento das poucas produções manufatureiras vigentes, a maximização dos impostos sobre as já decrescentes produções minerais e, por fim, a derrama, de modo a alcançar o mínimo de ouro estipulado pela Coroa portuguesa. Segundo Sérgio Buarque de Holanda (2003, p. 440), "a Coroa Portuguesa, tendo por base de cálculo uma produção média de 500 arrobas de ouro por ano, estabeleceu em 1750 que o rendimento anual do quinto deveria ser de 100 arrobas”, sendo que para completá-la, quando não alcançada, "elaborou a técnica tributária da derrama, que consistia na exigência de que a população pagasse a diferença".

Concomitantemente, consolidava-se no seio de parte da elite mineira um papel de consciência de que após a descoberta e a exploração das riquezas minerais, Minas Gerais passou a ser o alvo da maior atenção da Coroa, justamente em função de suas produções minerais. Economicamente, ao longo do Setecentos, a capitania havia se tornado contribuinte fundamental no processo de sustentação da economia da América portuguesa e da Coroa, conquanto ainda continuasse a ser tratada como periferia da periferia do Império.

Nesse ínterim, parte da elite e dos intelectuais locais, desgostosos e deslocados, procurava aliar-se estrategicamente em busca de reformas do sistema, buscando garantir a inserção de Minas Gerais e do Brasil sob novos patamares na balança de poder (SILVA, 1995; FURTADO, 2008 e 2009).

Apesar da sequência de pensamentos e movimentos que, nesse recorte histórico, buscaram maior autonomia para Minas Gerais e, consequentemente, para a própria elite da terra - e os seus interesses, Kenneth Maxwell (1978) considera que o que se viu ao longo do século seguinte foi um processo de acomodação das elites mineiras às novas conjunturas e reformas políticas propostas pela Coroa, com a devida aceitação às imposições metropolitanas, a exemplo dos esforços intelectuais orientados para o

\footnotetext{
${ }^{2}$ Pesquisa financiada pelo CNPq.
} 
reestabelecimento da América portuguesa, como Memória para o Melhoramento dos Domínios da América, de Dom Rodrigo de Sousa Coutinho, mas muito também em função da "frustação" do movimento sedicioso ou, ainda, pela diminuição da influência das elites mineradoras face à suposta inflexão agrícola que se viu a partir dos primeiros anos do novo século (IGLÉSIAS, 1958, p. 61-62). ${ }^{3}$

\section{Joaquim Veloso de Miranda: "naturalista a serviço do Rei"}

Apesar das propostas que partiam daqueles que buscavam uma maior autonomia para a capitania de Minas Gerais, também é possível encontrar súditos da Coroa portuguesa, igualmente naturais da terra, que não mediram esforços para implementar as propostas da Coroa portuguesa neste lado do Atlântico, com o objetivo de reavivar a economia luso-brasileira e as percepções econômicas do Reino.

Um desses expoentes foi o naturalista luso-brasileiro Joaquim Veloso de Miranda. Natural do Inficionado, termo da Cidade de Mariana, Veloso de Miranda nasceu no ano de 1746, filho de Francisco, imigrante português que teve por caixeiro a primeira profissão nas Minas, alçando a confiança de um rico e eminente minerador local, igualmente português, por nome Paulo Rodrigues Durão, desposando sua filha.

Como filho primogênito e de família possuidora de avultadas fazendas, o jovem Joaquim Veloso de Miranda frequentou o Seminário de Nossa Senhora da Boa Morte, na Cidade de Mariana, tornando-se clérigo e transladando-se para Portugal logo após, onde assentou matrícula no curso de Cânones da Universidade de Coimbra. No âmbito das reformas universitárias de 1772, matriculou-se no recém inaugurado curso de Matemática, onde envolveu-se profissionalmente com o lente de Ciências Naturais, o paduano Domenico Vandelli, com quem compartilharia experiências e conhecimentos acadêmicos, sobretudo na área da Botânica.

Alegando interesse próprio após conquistar o título de doutor em Ciências Naturais, Veloso de Miranda retornou da Corte no ano de 1779, passando a atuar como

\footnotetext{
${ }^{3}$ A suposta substituição da mineração pelas atividades agrícolas na capitania teria proporcionado que Minas Gerais passasse incólume à suposta crise que, na historiografia, respondeu por vários nomes como "inflexão agrícola", "decadência mineira", "crise da mineração", "crise da descapitalização" ou ainda "crise da regressão econômica", figurando na historiografia brasileira há até algum tempo (FURTADO, 1982). Na verdade, autores como Kenneth Maxwell (1978, p. 110), José Ferreira Carrato (1986) e Manolo Florentino (1995, p. 47) demonstraram que a população mineira pouco flutuou com a diminuição da produção aurífera. Pelo contrário. Maxwell, em especial, assinala que entre 1776 e 1821, um ano antes da capitania ter sido transformada em província, a população da Comarca do Rio das Mortes quase triplicou, enquanto a de Vila Rica, declinou, demonstrando que não houve uma fuga de habitantes da capitania, conforme durante muito tempo se supôs, mas sim um êxodo rural que proporcionou uma reorientação econômica. De fato, ao longo de todo o Oitocentos Minas Gerais consolidaria sua vocação agropastoril.
} 
naturalista a serviço da Coroa portuguesa em Minas Gerais, realizando pesquisas botânicas no entorno da Cidade de Mariana e de Vila Rica logo após seu retorno, e maximizando sua zona de atuação ao longo do tempo, vindo a percorrer vasto território da capitania ao longo das duas décadas seguintes.

Posteriormente, Veloso de Miranda também ampliou seu leque de pesquisas, dedicando-se ainda à mineralogia e aos estudos montanísticos (a ciência dos metais, à época), sobretudo com estudos sobre o nitro, mineral de onde era extraído o salitre, componente da pólvora e uma das principais demandas portuguesas quanto ao seu processo produtivo na América portuguesa. Suas pesquisas, sobretudo aquelas em Botânica, foram fundamentais para a decisão régia da criação de um horto botânico em Vila Rica, o qual haveria de ser inaugurado em 1799 e entregue ao próprio naturalista, seu primeiro diretor.

Se a maioria das atividades de "indagações filosóficas"4 eram quase sempre desempenhadas por um filósofo naturalista, mais frequente era a presença de dezenas de auxiliares gravitando ao seu redor, dentre carregadores, riscadores e militares, como aquela realizada por Alexandre Rodrigues Ferreira (1970) na bacia amazônica e nas minas do Cuiabá, em que foi acompanhado, na ocasião, por um jardineiro botânico português, Agostinho Joaquim do Cabo (?-1789), por um astrônomo, o bolonhês Antônio José Landi (1713-1791), pelos riscadores portugueses José Codina (?-1793) e José Joaquim Freire (1760-1847), por alguns religiosos e ainda por duas centenas de militares, entre oficiais e graduados, portugueses e indígenas, outras tantas viagens filosóficas eram realizadas pelo naturalista e por não mais do que um ou dois auxiliares, os quais haveriam de ser responsáveis por múltiplas atividades, como o estabelecimento de um local para pouso, o preparo das comedorias, a guarda dos animais em pasto seguro e, quando da partida, toda a preparação dos animais, equipando-os para acomodar as bruacas, onde eram guardados todos os apetrechos da viagem e os acervos coletados. Para Ildeu Moreira (2015, p. 1059), "muitos foram os viajantes que souberam aproveitar a experiência das populações locais - indígenas ou não - e seu conhecimento das regiões visitadas" na América portuguesa e não raro era comum que os auxiliares fizessem às vezes de auxiliares técnicos dos naturalistas, atuando na coleta e no tratamento dos acervos recolhidos.

Ao longo de sua atuação como naturalista botânico Veloso de Miranda manteve intensa convivência com profissionais letrados, como o médico Luiz José de Godói

\footnotetext{
${ }^{4}$ Como eram designadas as pesquisas científicas à época.
} 
Torres, assim como ele formado na Universidade de Coimbra, ou ainda como o engenheiro Manoel Ribeiro Guimarães, responsável pelo projeto do horto botânico de Vila Rica e pelo planejamento e execução de outros serviços de engenharia em Vila Rica, como a reordenação urbana do alto do Morro de Santa Quitéria, atual praça Tiradentes, e pelo projeto da nova casa da Câmara e Cadeia, atual Museu da Inconfidência, também atuou o naturalista com outros profissionais práticos de ofício, livres e cativos que enquanto seus auxiliares foram igualmente importantes para que o naturalista pudesse desenvolver suas pesquisas em História Natural.

Ao longo do presente estudo, objetivamos ressaltar a importância desses auxiliares no desenvolvimento das Ciências Naturais na capitania de Minas Gerais, no âmbito das pesquisas realizadas pelo naturalista Joaquim Veloso de Miranda, quando da virada do século XVIII para o século seguinte.

\section{Pintores e riscadores: a arte e a Botânica}

Segundo o historiador Caio Boschi, o pintor e riscador Apolinário de Souza Caldas (1762/3-1806) foi "o mais conhecido e duradouro colaborador de Veloso de Miranda na arte da pintura e do risco" (BOSCHI, 2012, p. 128-129). Além de seus conhecimentos de ofício, era militar tendo assentado praça como soldado no Regimento de Cavalaria a 8 de março de 1779, aos 17 anos de idade (AHU, MG, Cx. 188, Doc. 35, Cód. 13880). Sua trajetória profissional, no entanto, o relega à posteridade por sua atuação junto ao naturalista Veloso de Miranda, responsável pela confecção de mais de trezentos desenhos de plantas na primeira grande viagem filosófica realizada por este naturalista mineiro, entre os anos 1781 e 1782 (PATACA; PINHEIRO, 2005), servindo-o "pela sua arte de pintura e desenho para delinear as plantas, sem outro interesse mais que seu soldo" (AHU, MG, Cx. 188, Doc. 35, Cód. 13880).

Apesar da produção vultuosa, sabe-se que grande parte de seus trabalhos se perdeu, provavelmente durante o processo de translado do material relativo à História Natural desde o Real Jardim Botânico da Ajuda, em Lisboa, para o Muséum d'Histoire Naturelle, de Paris, quando da invasão napoleônica comandada pelo General JeanAndoche Junot (1771-1813), em Portugal, no ano de 1808.

Ao longo dos primeiros anos do século XIX, Apolinário buscou o devido reconhecimento por sua produção artística e trajetória como militar. Para tanto, alegou ter prestado "relevantes serviços", demonstrando-se esperançoso por receber as devidas recompensas, na forma de uma promoção militar, requerendo promoção ao posto de 
tenente no regimento de Vila Rica, tendo confeccionado uma petição composta de várias declarações, assinadas por autoridades e por pessoas com quem havia servido. $\mathrm{Na}$ oportunidade, Veloso de Miranda afirmou que o riscador o havia acompanhado na qualidade de pintor "na diligência em que andei pela maior parte desta capitania a recolher e observar os produtos naturais (...), [e] cumpriu muito bem com as obrigações do que por mim era encarregado àquele respeito por ser bastantemente hábil no desenho" (AHU, MG, Cx. 188, Doc. 35, Cód. 13880)., O naturalista José Vieira Couto também lançou elogios a Apolinário, afirmando que o riscador havia participado de uma viagem filosófica por ele realizada na região por ele denominada "Nova Lorena Diamantina", "em cujos serviços mostrou com muito zelo e atividade no mesmo Real Serviço" (AHU, MG, Cx. 188, Doc. 35, Cód. 13880).

Apesar de sua súplica e dos depoimentos, Apolinário não teve seu pedido deferido. Num último esforço pelo seu reconhecimento, viajou para Lisboa para "representar e pedir a Vossa Majestade a devida recompensa". Sua chegada à Corte, no entanto, coincidiu com a "retirada de Vossa Majestade para o Rio de Janeiro, por consequência da invasão do Exército Francês neste Reino" (AHU, MG, Cx. 188, Doc. 35, Cód. 13880), tendo sido Apolinário aproveitado durante "três anos no Regimento de Cavalaria [do Caes, atual Regimento] no 7", em Lisboa. "Vendo, porém, que pela sua idade nunca seria promovido, requereu passagem para o seu primeiro regimento, e estando em arranjos para a viagem, sobrevieram moléstias e incômodos que o impediram" de transpor o Atlântico de volta à América (AHU, MG, Cx. 188, Doc. 33, Cód. 13874).

Em 9 de setembro de 1822 Apolinário ainda aguardava em Lisboa a promoção que solicitara há quase vinte anos (AHU, MG, Cx. 188, Doc. 33, Cód. 13874), o que ocorreu somente no ano seguinte, com a indicação de

fazer-lhe mercê de dar passagem para o seu primeiro Regimento de Cavalaria de Minas Gerais, no posto de $1^{\mathrm{o}}$ tenente, ou a conseguir uma pensão com que o suplicante possa passar o resto da sua vida nesta Capital, visto achar-se privado dos meios de subsistência (AHU, MG, Cx. 188, Doc. 35, Cód. 13880).

Nada mais sabe-se a seu respeito, se permaneceu na Corte ou se retornou à América.

Outro riscador que muito auxiliou Veloso de Miranda em suas viagens filosóficas foi José Gervásio de Souza Lobo (1758?-1806).Assim como Apolinário, José Gervásio 
era militar de profissão e desde a década de 1770 percorria frequentemente o Caminho Novo, em direção ao Rio de Janeiro, conduzindo enquanto escolta as produções minerais da capitania para aquele porto (APM, CC; Cx. 18, Rolo 506, Doc. 10377). Outra atuação que se destaca em sua trajetória militar foi o sua participação, no ano de 1777 , de atividades militares mais além da capitania, tendo se deslocado para a região Sul, para lutar contra os espanhóis (APM, CC, Cx. 31, Rolo 510, Doc. 10634.)

Brevemente biografado por Adalgisa Arantes Campos (2002), José Gervásio assentou praça no Regimento de Cavalaria de Vila Rica a 22 de junho de 1767, fazendo o "juramento de fidelidade ao Estandarte" em "10 de julho de 1775" (AHU, MG, Cx. 148, Doc. 18, Cód. 11377). Naquele núcleo urbano, era morador e possuidor de uma residência à Rua de São José, após a ponte (MATHIAS, 1969, p. 93).

Apesar de determinadas fontes afirmarem que José Gervásio era português, natural da freguesia de Cabeceira de Bastos, próxima a Braga (AHU, MG, Cx. 148, Doc. 18, Cód. 11377), ele também foi descrito como sendo "mestiço", o que talvez justifique o fato de pouco ter ascendido na carreira militar, exercendo não mais do que funções graduadas como cabo de esquadra e picador (AHU, Minas Gerais, Cx. 148, Doc. 18, Cód. 11377).

Diferentemente de Apolinário, no ano de 1797, depois de 30 anos de serviço, solicitou enquanto promoção uma Carta Patente para o posto de "capitão da Companhia de Infantaria Auxiliar dos Homens Pardos dos distritos de Montevidéu, Onça e Piedade”, do termo de São João del-Rei, sendo prontamente deferido (APM, CC, Cx. 148, Doc. 18, 1799-1804).

Em relação à sua atuação enquanto auxiliar de Veloso de Miranda, José Gervásio acompanhou o naturalista em algumas viagens filosóficas na década de 1790 (MATHIAS, 1969, p. XXVII). Um diferencial, no entanto, chama a atenção: José Gervásio provavelmente foi preparado para tal, o que se pode constatar em uma correspondência do então governador da capitania, o Visconde de Barbacena, para Martinho de Melo e Castro, datada de 1790, afirmando que havia mandado aperfeiçoar um soldado do Regimento "nesta arte, e [que ele] se acha[va] demais adiantado com o uso, depois das poucas lições com que se habilitou" (AHU, MG, Cx. 134, Doc. 56, Cód. 10513). Apesar dessa informação, não se sabe de quem teria sido discípulo nas artes das tintas e dos pincéis, conquanto tenha sido contemporâneo em Vila Rica de Manoel da Costa Ataíde (1762?-1830) e Manoel Ribeiro Rosa (1758-1808), esse último como ele mestiço e militar (CAMPOS, 2012, p. 250). 
Ainda em relação à sua formação, Gustavo Ferreira afirma que esta provavelmente era diferenciada, conjecturando que em algum momento José Gervásio teve

\begin{abstract}
contato com livros sobre desenho, na busca por referências de sua instrução, tendo em vista as obras seguramente de sua autoria, como os Novíssimos dos Homens (...). [Por meio delas], percebe-se que este conhecia, por exemplo, as gravuras dos irmãos Joseph Sebastian Klauber (1710-1768) e Johann Baptist Klauber (1712-1787), gravadores oficiais do Bispo de Augsburgo, autores de estampas com temas religiosos durante o século XVIII e de muita aceitação pública, portanto possuía alguma instrução e referência na arte do desenho (CAMPOS, 2012, p. 329-340).
\end{abstract}

Para além dos auxílios que prestou ao naturalista mineiro, José Gervásio também atuava frequentemente enquanto pintor de ofício. Em Vila Rica, foi responsável, nos anos de 1792 e 1793, por um trabalho de pintura para a Irmandade do Rosário dos Pretos, de quem era irmão professo e, poucos anos depois, entre 1798 e 1803, pela "pintura e o douramento dos altares laterais de Santo Antônio, São Benedito e Santa Efigênia", naquele mesmo templo (CAMPOS, 2008, p. 16), bem como pelos "quatro painéis sobre os novíssimos do homem (a Morte, o Juízo, o inferno e o Paraíso)", hoje expostos na Matriz do Pilar, em Ouro Preto (CAMPOS, 2012, p. 249).

Campos (2012) afirma que José Gervásio também foi o responsável pela realização de um conjunto de pinturas no antigo Palácio de Cachoeira do Campo, em 1780. Em outro momento, em 1788, teria se deslocado à São João del-Rei, onde teria realizado um trabalho da pintura na residência do intendente local, Joaquim José Soares de Araújo (CAMPOS, 2012). Além de trabalhos realizados em igrejas e para particulares, há notícias de que também desempenhava outros trabalhos menores, como aquele que fez nas urnas da loteria então vigente na capitania (APM, CC, Cx. 137, Rolo 541, Doc. 21191).

Não deixa de ser interessante o fato de que Gervásio deixou de exercer a profissão militar após 32 anos de exercício, em função de problemas de saúde, provavelmente decorrentes do contato constante com as tintas e, mais precisamente, com o chumbo de sua composição, recebendo atestado assinado pelo médico do Regimento, Antônio José Vieira de Carvalho (AHU, MG, Cx. 148, Doc. 19, Cód. 11376.).

\title{
Escravos afeitos à História Natural
}

Além dos pintores e riscadores (desenhistas) profissionais práticos de ofício que possuíam a responsabilidade de registrar no papel as amostras botânicas coletadas, era 
hábito comum a condução de escravos pelos naturalistas, quando de suas viagens filosóficas, os quais deveriam auxiliá-lo nas atividades inerentes ao empreendimento. Segundo Ildeu Moreira (2015, p. 1051), era comum a presença de escravos nas viagens filosóficas realizadas ao longo dos séculos XVIII e XIX, mencionando ainda o destaque que o pintor francês Jean-Baptiste Debret (1768-1848) a alguns deles, a quem chamou de "negros naturalistas", que "atuavam como guias e serviçais, além de ser frequentemente hábeis caçadores e coletores de espécimes" (MOREIRA; MASSARANI; ANTUNES, 2015, p. 1055). Por esses préstimos, frequentemente os viajantes naturalistas se aproveitavam da experiência e dos conhecimentos desses auxiliares quando de seus empreendimentos.

Com Veloso de Miranda não foi diferente. Em todas as viagens filosóficas que realizou, o naturalista mineiro se fez acompanhar de escravos que tinham múltiplas responsabilidades, como preparar as cargas para o transporte nos muares, conduzi-los em meio aos caminhos e picadas percorridos, preparar a alimentação da jornada, a montagem do acampamento e, não raro, auxiliar o naturalista na recolha e na preparação das amostras.

Por intermédio da Lista do cálculo da despesa da Real Fazenda com a exploração e estabelecimento do Jardim botânico de Ouro Preto (APM, CC, Cx. 18, Doc. 10367, Rolo 506) foi possível constatar que entre o segundo semestre de 1796 e os primeiros meses do ano seguinte, quando Veloso de Miranda realizou uma viagem filosófica à região do rio São Francisco, foi acompanhado por uma comitiva, viajando "protegido por uma escolta de sertanistas" onde constavam alguns escravos, em número incerto (PONTES, 1844, p. 284e-284g). Nesta ocasião, Veloso de Miranda foi o responsável pela descoberta de prósperas minas de galena "nas cabeceiras setentrionais do rio Abaeté" (PONTES, 1844, p. 284-284F), mineral rico em chumbo e bastante utilizado à época na mineração de prata. Em outro momento, entre outubro de 1798 e janeiro de 1799, Veloso de Miranda se fez acompanhar por cinco escravos que o auxiliaram na recolha, na preparação e na embalagem de "48 caixotes de plantas vivas que o governador Lorena logo despachou para Lisboa" (APM, SC- 276, fl. 42v).

Ainda por intermédio da Lista do cálculo da despesa da Real Fazenda (...) (APM, CC, Cx. 18, Rolo 506, Doc. 10367), é possível constatar que Veloso de Miranda valeu-se do auxílio de escravos quando de suas viagens filosóficas em outros momentos, como naquela realizada no ano de 1787, onde consta o "pagamento do escravo", subentendendo-se como apenas um cativo; na viagem filosófica realizada no ano de 1791, 
quando foi acompanhado por "escravos", no plural, em número não especificado ou, ainda, no ano de 1792, também com a presença de um escravo.

Apesar de todas as informações presentes no documento em questão, não é possível averiguar quem eram os proprietários dos escravos em foco, conquanto houvesse a possibilidade do naturalista ter recebido compensações financeiras por utilizar seus próprios escravos nos empreendimentos filosóficos realizados para o Estado português, o que é justificável face à necessidade de que os mesmos fossem devidamente instruídos nas artes do preparo e do acondicionamento de amostras da História Natural, hipótese que pode ser corroborada por dado comentário registrado pelo naturalista francês Auguste de Saint-Hilaire (1779-1853), alguns anos após o falecimento de Veloso de Miranda, ao afirmar em uma de suas memórias que o naturalista mineiro não herborizava sozinho, mas “por intermédio de seus escravos” (SAINT-HILAIRE, 2011, p. 84).

\section{Considerações Finais}

Embora tenham sido mencionados na correspondência entre as autoridades mineiras e metropolitanas, são pouco expressivas as informações que a historiografia dispõe desses personagens, que se mostraram fundamentais para o desenvolvimento e o estudo das Ciências Naturais na capitania de Minas Gerais.

Contribui ainda para essa ausência de informação, o fato de que os diários de viagens de Veloso de Miranda, ou ainda suas memórias de viagens, jamais terem sido encontrados, os quais seriam fundamentais para maximizar essa dada importância e, sobretudo, por descortinar ainda mais a participação desses personagens periféricos do âmbito das ciências deste lado do Atlântico.

Dentre as publicações que nos são conhecidas, não se fazem presentes menções sobre a atuação desses personagens quando da realização das viagens filosóficas de Veloso de Miranda, como no artigo "Plantas medicinais indígenas de Minas Gerais", publicado no ano de 1814 na revista portuguesa $O$ Patriota pelo médico e cirurgião Luiz José de Godói Torres, considerado o mais expressivo colaborador de Veloso de Miranda no estudo da botânica mineira, no qual inexistem quaisquer referências à participação de auxiliares no processo de coleta, preparação e classificação dos exemplares botânicos. Mesmo dentre aquelas publicações atribuídas à Veloso de Miranda, mais afamadas, como as pranchas no Florae et Faunae Lusitanicae Specimen, publicado por Vandelli em 1788, mas composto basicamente pelos estudos realizados por Veloso de Miranda, no qual se encontram ainda parte das pranchas que são atribuídas ao riscador e pintor Apolinário de 
Souza Caldas, cujas cópias foram enviadas também ao botânico inglês Joseph Banks, em Londres, com quem Vandelli nutria admiração profissional, e hoje fazem parte do acervo do The Natural History Museum, de Londres (FERREIRA, 2012, 146-148).

Embora suprimidos nas memórias de viagens e nas demais publicações delas resultantes, nos quais eram personagens fundamentais, certamente tais empreendimentos seriam pouco eficientes se não fossem considerados seus conhecimentos tradicionais e de apoio logístico e técnico, pelo que trazer à luz da historiografia a participação desses personagens é resgatar a presença e participação desses indivíduos que tão de perto acompanharam e colaboraram com as viagens filosóficas e com as demais atividades de ciências realizadas na América portuguesa nesse recorte histórico em questão. Não por coincidência, recentes estudos vêm inserindo alguns desses personagens na nova historiografia das ciências e das artes, como o próprio José Gervásio de Souza Lobo, considerado por Joelson Biltran Trindade (1988, p. 123) como autor de uma “"excentricidade da invenção audácia do colorido', não tendo antecedentes nem similitudes entre outros pintores da capitania mineira".

\section{Referências}

\section{Fontes Primárias}

\section{Arquivo Histórico Ultramarino, Minas Gerais}

AHU, MG, Cx. 134, Doc. 56, Cód. 10513. Carta do Visconde de Barbacena, governador das Minas Gerais, enviando quatro caixas de produtos minerais e vegetais, e junto suas relações. Vila Rica, 12 de junho de 1790.

AHU, MG, Cx. 148, Doc. 18, Cód. 11377. Certidão de Pedro Afonso Galvão de São Martinho, tenente-coronel Comandante do Regimento de Cavalaria das Minas, atestando que Gervásio de Souza Lobo, soldado da $1^{\text {a }}$ Companhia, assentou praça de soldado em 1767, julho, 22. Vila Rica, 4 de abril de 1799.

AHU, MG, Cx. 148, Doc. 19, Cód. 11376. Atestado de Antônio José Vieira de Carvalho, cirurgião-mor do Regimento de Cavalaria Regular das Minas, certificando de Gervásio de Souza Lobo, picador do dito Regimento, padece de moléstia, pelo que está impedido de continuar no seu ofício. Vila Rica, 5 de abril de 1799.

AHU, MG, Cx. 188, Doc. 33, Cód. 13874. Requerimento (minuta) de Apolinário de Sousa Caldas, furriel da Cavalaria de Linha das Minas Gerais, pedindo promoção ao posto de alferes ou de tenente de seu Regimento. Vila Rica, 9 de setembro de 1822.

AHU, MG, Cx. 188, Doc. 35, Cód. 13880. Requerimento do furriel Apolinário de Sousa Caldas, que acompanhou um cientista na descoberta da Nova Lorena Diamantina, designado também para acompanhar o naturalista Joaquim Veloso de Miranda na exploração dos produtos botânicos pintando e desenhando as plantas, solicitando a sua 
passagem para o $1^{\circ}$ Regimento de Cavalaria de Minas Gerais, no posto de tenente. Minas Gerais, 7 de janeiro de 1825.

AHU, MG, Cx. 188, Doc. 35, Cód. 13880. Requerimento do furriel Apolinário de Sousa Caldas, que acompanhou um cientista na descoberta da Nova Lorena Diamantina, designado também para acompanhar o naturalista Joaquim Veloso de Miranda na exploração dos produtos botânicos pintando e desenhando as plantas, solicitando a sua passagem para o $1^{\circ}$ Regimento de Cavalaria de Minas Gerais, no posto de tenente. Minas Gerais, 7 de janeiro de 1825.

\section{Arquivo Público Mineiro}

APM, CC, Cx. 18, Rolo 506, Doc. 10367. Lista do cálculo da despesa da Real Fazenda com a exploração e estabelecimento do Jardim botânico de Ouro Preto. Vila Rica, 21 de agosto de 1806.

APM, CC, Cx. 18, Rolo 506, Doc. 10377. Recibo passado por Gervásio de Souza Lobo ao capitão Braz Alves Antunes referente ao pagamento dos direitos das entradas. Vila Rica, 14 de março de 1775.

APM, CC, Cx. 31, Rolo 510, Doc. 10634. Atestado de idoneidade passado por Sebastião José de Souza Ferraz para Gervásio José de Souza sobre os bons serviços prestados na expedição das fronteiras do Sul. Onça, 19 de abril de 1785.

APM, CC; Cx. 73, Rolo 523, Doc. 30814. Carta de José de Souza Gonçalves ao escrivão deputado da Junta da Real Fazenda, Carlos José da Silva, sobre o envio dos rendimentos das entradas, pelo soldado dragão Gervásio de Souza Lobo. São João delRei, 11 de março de 1775.

APM, CC; Cx. 77, Rolo 524, Doc. 20071. Recibo passado por Gervásio de Souza Lobo ao administrador do registro do caminho novo, Manuel do Vale Amado, referente à entrega de ouro em pó e em barra. Registro do Caminho Novo, 03 de novembro de 1771 .

APM, CC; Cx. 77, Rolo 524, Doc. 20072. Recibo passado por Gervásio de Souza Lobo ao administrador do registro do caminho novo, Manuel do Vale Amado, referente à entrega de ouro em pó e em lavra. Registro do Caminho Novo, 04 de julho de 1776.

APM, CC; Cx. 79, Rolo 525, Doc. 20120. Recibo passado por Gervásio de Souza Lobo ao capitão Manuel do Vale Amado, referente à entrega de quantia no Tribunal da Junta de Vila Rica. Vila Rica, 03 de outubro de 1775.

APM, CC, Cx. 137, Rolo 541, Doc. 21189. Recibos pela redação dos bilhetes da loteria. Vila Rica, S/D.

APM, CC, Cx. 137, Rolo 541, Doc. 21191. Recibo passado por José Gervásio de Souza ao capitão Domingos de Amorim Lima, referente à entrega de quantia de ouro pelo pagamento das pinturas das urnas da loteria. Vila Rica, 28 de abril de 1799.

\section{Fontes Impressas}

FERREIRA, Alexandre Rodrigues. Viagem filosófica às Capitanias do Grão-Pará, Rio Negro, Mato Grosso e Cuiabá. São Paulo: Gráfica Brunner, 1970. 
PONTES, Manoel José Pires da Silva. Memória da Comarca da Pitangui. Revista do Instituto Histórico e Geográfico Brasileiro, tomo VI. Rio de Janeiro: Kraus Reprint, 1844.

SAINT-HILAIRE, Auguste de. História das plantas mais notáveis do Brasil e do Paraguai. Belo Horizonte: Fino Traço, 2011.

TORRES, Luiz José de Godói. Plantas medicinais indígenas de Minas Gerais, pelo Doutor Luiz José de Godoy Torres, Physico das tropas daquella Cappitania. O Patriota, no 3, maio-jun. 1814.

VANDELLI, Domenico. Florae Lusitanicae et Brasiliensis specimen. Et Epistole ab Eruditis Viris Carolo a Linné, Antonio de Haen ad Domenicum Vandelli Scriptae. Coimbra: Typographia Academico-Regia, 1788, 96 p. Disponível em: http://bibdigital.bot.uc.pt/obras/UCFCTBt-B- 78-1-24b/globalItems.html. Acesso em: 12 de novembro de 2016.

\section{Referências}

BOSCHI, Caio César. "Os Secretários do Governo da Capitania de Minas Gerais". BOSCHI, Caio César. Exercícios de Pesquisa Histórica. Belo Horizonte: Editora PUC Minas, 2012, p. 59-100.

CAMPOS, Adalgisa Arantes. A contribuição de José Gervásio de Souza Lobo para a pintura colonial. Anais do XXVII Colóquio do Comitê Brasileiro de História da Arte. Belo Horizonte: C/ Arte, 2008.

CAMPOS, Adalgisa Arantes. Dois pintores mestiços em um mesmo canteiro de obras. In: PAIVA, Eduardo França \& ANASTASIA, Carla Maria Junho (org.). O trabalho mestiço: maneiras de pensar e formas de viver - séculos XVI a XIX. São Paulo: Annablume; Belo Horizonte: PPGHIS/UFMG, 2002.

CAMPOS, Adalgisa Arantes. Notas sobre um pintor luso-brasileiro e a iconografia dos novíssimos (a morte, o juízo, inferno e o paraíso) em fins da época colonial. Revista de História e Estudos Culturais, Vol. 9, ano IX, nº 2, Maio-Ago. 2012.

CAMPOS, Adalgisa Arantes. Dois pintores mestiços em um mesmo canteiro de obras. In: PAIVA, Eduardo França \& ANASTASIA, Carla Maria Junho (Org.). O trabalho mestiço: maneiras de pensar e formas de viver - séculos XVI a XIX. São Paulo: Annablume; Belo Horizonte: PPGHIS/UFMG, p. 249-254, 2002.

CARRATO, José Ferreira. Igreja, Iluminismo e Escolas Mineiras Coloniais. São Paulo: Nacional, 1986.

FERREIRA, Gustavo Oliveira. As polêmicas Flores: Joaquim Veloso de Miranda e a prática científica nas Minas Setecentistas. Rio de Janeiro, 2013 (Dissertação de Mestrado em História das Ciências e da Saúde, Fundação Oswaldo Cruz).

FLORENTINO, Manolo. Em costas negras. Rio de Janeiro: Arquivo Nacional, 1995. FURTADO, Júnia. Iluminuras da Sedição: A cartografia de José Joaquim da Rocha e a Inconfidência Mineira. In: CAMPOS, Adalgisa. Território, Arte e Sociedade. Ouro Preto: C/Arte, 2008, p. 981-1003.

FURTADO, Júnia. Um cartografo rebelde? José Joaquim da Rocha e a cartografia de Minas Gerais. Anais do Museu Paulista, vol. 14, p. 155-187, 2009. 
HOLANDA, Sérgio Buarque de (org). História Geral da Civilização Brasileira. Tomo 1. A Época Colonial. Volume 2. Rio de Janeiro: Bertrand Brasil, 2003.

MATHIAS, Herculano Gomes. Um recenseamento na Capitania de Minas Gerais. Vila Rica, 1804. Rio de Janeiro: Arquivo Nacional, 1969.

MAXWELL, Keneth. A Devassa da Devassa. Rio de Janeiro: Paz e Terra, 1978.

MOREIRA, Ildeu; MASSARANI, Luisa; ANTUNES, Anderson. O descanso dos naturalistas: uma análise de cenas na iconografia oitocentista. História, Ciências, Saúde-Manguinhos, vol. 22, no. 3, p. 1051-1066, Jul.-Set. 2015.

PATACA, Ermelinda Moutinho; PINHEIRO, Rachel. Instruções de viagem para a investigação científica do território brasileiro. Revista da SBHC, Rio de Janeiro, vol. 3, $\mathrm{n}^{\mathrm{o}} .1$, p. 58-79, jan.-jun. 2005.

REZENDE, Leandro Gonçalves de; LEOPOLDINO, Armando Magno de Abreu. Pintores coloniais nas minas setecentistas: a vez de Manoel Ribeiro Rosa. Anais do VIII Encontro de História da Arte. Campinas: Unicamp, 2012, p. 329-340.

SILVA, Maria Beatriz Nizza da. Um brasileiro nas malhas da Inquisição: o mineiro José Joaquim Vieira Couto e a Maçonaria. In: SILVA, Maria Beatriz Nizza da. Cultura portuguesa na Terra de Santa Cruz. Lisboa: Estampa, 1995, p. 249-264.

TRINDADE, Joelson Biltran. Artistas pardos de Minas Gerais: ARAÚJO, Emanuel. A mão afro-brasileira: significado da contribuição artística e histórica. São Paulo: Tenenge, 1988. 